\title{
FORNER PERIODISTA: LAS COLABORACIONES EN EL DIARIO DE LAS MUSAS (1790-1791)
}

\author{
PIEDAD Bolaños DONOSO \\ Universidad de Sevilla \\ JESÚS CAÑAS MURILlO \\ Universidad de Extremadura
}

\section{Resumen}

En este artículo se rescata del olvido las colaboraciones publicadas, como anónimas, por Juan Pablo Forner en uno de los diarios prestigiosos que aparecieron en el siglo XVIII español, el Diario de las Musas. Se incluyen los tres textos que el propio emeritense reconoció como suyos en el Catálogo de las obras de Forner de su misma mano: el Dialogo entre un Escolar y un Sabio à la moda, La Farsa de los Filósofos, y Diálogo entre el Doctor Ferrando y Mr. Pedant. Con nuestro trabajo hemos querido contribuir a mejorar el conocimiento que hoy se tiene de la producción escrita legada por Forner a la posteridad, y a difundirla entre los lectores actuales interesados.

Palabras clave: historia literaria, siglo XVIII español, teatro, periódicos, Juan Pablo Forner.

FORNER JOURNALIST: COLLABORATIONS IN DIARIO DE LAS MUSAS (1790-1791)

\begin{abstract}
This article rescued from oblivion the collaborations published, as anonymous, by Juan Pablo Forner in one of the prestigious newspapers that appeared in the Eighteenth Century in Spain, the Diario de las Musas (Journal of the Muses). These collaborations include the three texts that the native of Merida himself recognized as his own in the Catálogo de las obras de Forner de su misma mano: Dialogo entre un Escolar y un Sabio à la moda, La Farsa de los Filósofos and Diálogo entre el Doctor Ferrando y Mr. Pedant. With our work we wanted to contribute to improve the knowledge we have today of the written production bequeathed by Forner to posterity, and to disseminate it among current interested readers.

Keywords: literary history, Spanish Eighteenth century, theatre, newspapers, Juan Pablo Forner.
\end{abstract}


La colaboración de Juan Pablo Forner (1756-1797) en los periódicos de su época, y la utilización de la prensa como medio de dar a conocer parte de su producción, es una constante en la actividad literaria de nuestro extremeño, especialmente en los últimos años de su vida. A través de este tipo de publicaciones difunde artículos de opinión, textos de pensamiento, obras de polémica y de debate, poemas y otras obras de creación, algunas de las cuales se mueven en la órbita de los mundos del arte dramático.

Algunas de las controversias más famosas que tuvieron como centro escritos aportados por Forner, se desarrollaron en periódicos, como la que versó sobre la Oración apologética por la España y su mérito literario, difundida a través de El Censor, el Correo de los ciegos (también llamado Correo de los Ciegos de Madrid), El Apologista universal... (Cañas Murillo, 1997: 27-29); la que versó sobre el estreno madrileño de El Filósofo enamorado, iniciada en el Diario de Madrid (Bolaños Donoso y Cañas Murillo, 2021b); o la que se inició con motivo del estreno gaditano de esta misma comedia, iniciada, y concluida, en el Diario de Cádiz (Bolaños Donoso y Cañas Murillo, 2021a).

En el presente artículo nos vamos a ocupar de dar a conocer varios textos de Juan Pablo Forner publicados, anónimos, en otro de los periódicos del momento, el Diario de las Musas (DiMu en adelante). El propio emeritense dejó en sus "Papeles inéditos» indicaciones que son útiles para identificar las obras que se insertaron en esa publicación y que salieron de su pluma. Jiménez Salas (1944) se encargó de dar a conocer el Catálogo de las obras de Forner de su misma mano (Papeles de Grinda, Leg. 5. , hojas 1 y 2). En esta relación de obras propias, Forner inserta la siguiente aclaración: «en el Diario de las Musas1 hay tambien una invencion mia, con el título de La Farsa de los Filosofos; y dos Dialogos uno entre un Bachiller y un Moderno; y otro entre un Pretendiente y un Charlatan»(Jiménez Salas, 1944: 590).

Examinado el DiMu hemos conseguido localizar esas composiciones. Aparecen en los años 1790 y 1791. De los escritos citados por el emeritense, dos se hallan cercanos al mundo de la dramática, el llamado Diálogo entre un Bachiller y un Moderno, y el llamado Diálogo entre un

\footnotetext{
${ }^{1}$ La cursiva es nuestra.
} 
Pretendiente y un Charlatan; el tercero es un artículo periodístico de carácter ideológico, en el que se cuenta algunas anécdotas para hacerlo más atractivo, y se ofrecen ciertas opiniones y visiones de la realidad. Son, por orden de impresión en el periódico, los siguientes textos:

1) [Diálogo entre un Bachiller y un Moderno], publicado como Dialogo entre un Escolar y un Sabio à la moda (DiMu, 4, 4 de diciembre de 1790, págs. 15-17; y $D i M u, 5,5$ de diciembre de 1790, págs. 19-22).

2) La Farsa de los Filósofos (DiMu, 7, 7 de diciembre de 1790, págs. 27-29; y $D i M u, 10,10$ de diciembre de 1790, págs. 43-45).

3) [Diálogo entre un Pretendiente y un Charlatán], publicado como Diálogo entre el Doctor Ferrando y Mr. Pedant. (DiMu, 35, 4 de enero de 1791, págs. 145-148).

En el examen de los dos Diálogos insertos en el DiMu, el Dialogo entre un Escolar y un Sabio à la moda y el Diálogo entre el Doctor Ferrando y Mr. Pedant, existen muchos puntos de contacto, como podrá comprobarse en las páginas siguientes de este trabajo. No sólo en su estilo de redacción, sino también en sus contenidos, en los temas que trata, con posturas a veces totalmente coincidentes entre ambos. Son textos relacionados con las comedias, con las composiciones teatrales, pero también con las novelas o los relatos dialogados, con los tradicionales debates medievales, y con los diálogos renacentistas. Esa constituye la tradición en la que ambos se encuadran.

Con nuestro artículo queremos contribuir a mejorar el conocimiento que hoy se tiene de la producción escrita legada por Forner a la posteridad, y, en concreto, a las creaciones que antes hemos enumerado y que, hasta hoy, sólo fueron transmitidas por el DiMu en el siglo XVIII, y sin ser identificadas como obras compuestas por el emeritense, dado que no están firmadas y el verdadero nombre de su autor en ningún momento es especificado. Queremos, igualmente, proporcionar una mayor difusión, y acercarlas a los lectores interesados y a los especialistas actuales. 
Las reproducimos utilizando la única versión que conservamos, la incluida en el propio DiMu2.

La edición que hemos realizado tiene carácter paleográfico. En ella hemos respetado la grafía y puntuación que encontramos en el mencionado Diario. Con ella hemos pretendido facilitar el conocimiento y estudio de los usos ortográficos propios del siglo XVIII español. Hemos añadido la información sobre la parte del texto que se incluye en cada una de las páginas de que constan nuestras fuentes de información. Corregimos, indicándolo en la nota correspondiente, las escasas erratas que hemos detectado. Incluimos los textos por orden cronológico de publicación. Sólo insertamos anotaciones textuales. Actualmente los firmantes de este artículo tienen en preparación una edición completa, con las correspondientes anotaciones textuales, explicativas y eruditas, del teatro de Forner y de sus escritos relacionados con el mundo de la farándula. Allí incluiremos los dos Diálogos que ahora adelantamos a nuestros posibles receptores curiosos y deseosos de profundizar en la producción literaria de Juan Pablo Forner, y de tener un mayor, y más cabal y completo, conocimiento de esta.

${ }^{[15]}$ DIARIO DE LAS MUSAS.

DE 4. DE DICIEMBRE DE 1790.

Dialogo entre un Escolar y un Sabio à la moda .

Sab[io]. ¿Qué hay Bachiller? ¿cómo vá de pretensiones? [¿]Ha impreso Vmd. ya su relacion de meritos?

Es[colar]. En casa de Ibarra.

Sab[io]. ¿Y hay esperancillas? ¿Se han hallado buenos conductos?

Es[colar]. Tales quales, ya tengo dadas veinte esquelas.

Sab[io]. Ese es un gran merito. La relación supongo estará bien embutida de actos, de cursos, de regencias, y de oposiciones; no faltará su nemine

\footnotetext{
${ }^{2}$ Disponible en: <https://babel.hathitrust.org/cgi/pt?id=ien.35556000913343;view=1up;se $\mathrm{q}=1>$ (consulta: 15 de noviembre de 2020).

${ }^{3}$ En el Catálogo de sus obras, antes mencionado, Forner se refiere a este texto como «Diálogo [...] entre un Bachiller y un Moderno».
} 
discrepante, su valde condigno, y catate un sabio hecho y derecho, suficientisimo para vestir una toga.

Es[colar]. Asi se usa: asi lo mandan las leyes.

Sab[io]. ¡Patarata! ¿Quándo acabarán Vmds. de conocer que sus bachilleratos, y doctorados son la sentina de la barbarie?

Es[colar]. Seanlo en buen hora: esto me enseñaron. Por este camino me han conducido. Me inclinaron á los estudios desde mi niñez: naci sin mayorazgo: cuento 36. años cumplidos. ¿Quiere Vmd. que me ahorque?

Sab[io]. ¡Bella salida! digna de un Bachiller: y esos Doctores que fueron sus maestros; ¿qué derecho tienen para ser los mantenedores del pedantismo ${ }^{4}$ y la groseria?

Es[colar]. Les sucedió lo que á mi: son viejos y turpe putant quae in verbes didicere senes perdenda fateri, vea Vmd. como yo tambien se citar á Horacio: Pero amigo mio, ¿el saberle citar dá los puestos? [ं]dá el descanso de la vida? $[\dot{c}$ ]dá un ocio honesto que recompense las fatigas de la juventud? [i]Qué gran poeta, celebre historiador, eminente humanista, ha sido condecorado en España con la mitad de lo que logra un Rabula, azote de las familias, un Clerizonte nacido tal vez para Sacristan? ¿Qué nichos hay para colocar estos Idolillos? oigo zumbas de la turba multa de papelistas contra 1 os Doctores, $\mathrm{Ba}^{[16]}$ chilleres, Escolares, \&c. pero las oigo, y me rio, no de estos, sino de las zumbas. Vean nuestra legislacion; observen nuestra constitucion publica; reflexionen sobre una y otra, y dexense de andar por las ramas. Si la legislacion de Esparta permitia robar, ¿no seria un fatuo el que declamase contra el ladron?

Sab[io]. ¿Ola? ¿tambien el Señor Bachiller sabe erudiciones?

Es[colar]. Y las amo: pero no por eso me mofo de los que no las saben. Los Catones de nuestra literatura harian mejor en proponer medios solidos para mejorar nuestra constitucion publica, que en gastar ironías frias contra los Doctores. El Doctorado no es malo. Doctores fueron Arias Montano, Leon, Mariana, Antonio, Agustin, Nicolas Antonio, y otros semejantes. Y á fé que ya nos alegraramos de que los imitaran estos que se precian de Anti-Doctores. El mal está en otra parte, creame Vmd. y dar á trompa y talega sobre el pobre Bachiller que ha gastado su calor natural en una

\footnotetext{
${ }^{4}$ En $D i M u$, 'pedantisimo', por errata.
} 
carrera interminable para lograr alguna conveniencia en la vida, es una injusticia absurda.

Sab[io]. Ese es un efugio cabiloso. El Gobierno lo fomenta todo: ¿negará Usted esta verdad?

Es[colar]. No soy tan iniquo: lo veo y lo celebro.

Sab[io]. Pues ¿por qué no se mejoran las escuelas? ¿Por qué se enseña el Goudin aun en algunas?

Es[colar]. Porque se enseña.

Sab[io]. Seco es el Bachiller.

Es[colar]. Y el señor Pansofo es demasiado rudo, ó mas Bachiller que yo.

Sab[io]. Con que en suma, Vmd. nos querrá negar que las Matematicas, la Fisica experimental, la Chimica, la Botanica ¿las Humanidades de nada sirven?

Es[colar]. ¡Excelente Logica! [i]Logica censoria! Digame Vmd. varon doctisimo, exceptuando dos ó tres cátedras escasamente dotadas en algunas Universidades; ¿qué Togas, Prebendas, ó Beneficios ha habido hasta aqui para esa gente? $[\dot{i}]$ Qué estimulos han tenido? [i]un Fisico, mero Fisico, ha tenido hasta aqui puesto determinado á que aspirar? [i]Un Geometra ó astronomo, que no sean Artilleros ó Nauticos? ¿á donde han de ir con el fardo de su Astronomia, y Geometria? Nuestros Botanicos deben sin duda saber la Chimica, y la Botanica, ¿mas adonde habian de ${ }^{[17]}$ aprenderlas ahora veinte años? y viniendo á las Universidades: las dexaron corromper, y pegamos ahora contra ellas: ¡linda justicia! El interes y el honor son los lazarillos de la sabiduria. Lo que dá las dignidades, aquello florece. ¿Qué hubiera sido Neuton en España? Señor Pansofo: Vmd. que es tan doctazo, ¿por que no pretende que le hagan Visitador de las Escuelas publicas, para que armado de autoridad pueda reformarlas? Este medio, dicen algunos que sin ser reformadores con periodo entienden algo de achaques literarios, que haria mas fruto en un año que quanto con sus barrumbadas pueden hacer en veinte siglos estos Catones.

Sab[io]. Si me comisionaran á esa visita las destruiria enteramente.

Es[colar]. Cometeria Vmd. un disparate no menos garrafal que las befas de mis reformadores. El Carpintero debe aprender en el taller de carpinteria: y el Jurista, Teologo, Medico \&c. es menester que tengan tambien sus talleres. 
La suficiencia ha de experimentarse en el yunque, y este yunque son los actos y grados. Este uso es loable, y aun preciso. Entregar el Magisterio publico á quien no haya dado pruebas de que tiene suficiencia para enseñar, seria exponerse á grandes inconvenientes $\mathrm{El}$ toque está en que estas pruebas sean, lo que deben, y en este caso un hombre de carrera, chillen quanto quieran los señores criticos, es muy preferible á qualquiera erudito de miscelanea.

(Se continuará)

${ }^{[19]}$ DIARIO DE LAS MUSAS.

DE 5. DE DICIEMBRE DE 1790.

Sigue el Dialogo de ayer.

Sab[io]. Estaba distraido ¿qué es eso de miscelanea?

Es[colar]. Me explicaré. Viene un pretendiente á Madrid provisto de unos malos elementos de Gramatica. Oye en los cafés hablar magistralmente de Ciencias, de Artes, de erudicion, de Economia, de Nautica, de Comercio, de Politica \&c. lee los Papeles del tiempo: pilla quatro libros: salpica una especie aquí, otra alli, otra acullá: juzgase erudito y empieza á hacer numero entre los oraculos. Agarrase á los lugares comunes de la Moral, no saliendo nunca de las generalidades v. g. Las Ciencias exactas son utilisimas: los Doctores son unos pedantes; sin buen gusto no hay verdadero saber: la critica es la guia de las Ciencias: y otras tan reconditas é inauditas como estas; hace su papel en las concurrencias; y de golpe y porrazo ete aqui un hombre que sin otra carrera que la de hablador, se pondrá muy sencillamente á vomitar benablos contra las carreras de las Universidades, sin mas exâmen que la inspiracion de su vanidad. En Roma jamás fué Consul ningun Medico, ni ningun Arquitecto subio á los Rostros. Cada profesion tenia su carrera y su termino; y el que no se aplicaba á alguna determinadamente, era aborrecido de las leyes, y despreciado de sus conciudadanos.

Sab[io]. ¿Con qué en fin las carreras son utiles?

Es[colar]. No solo utiles, sino precisas: los que no son utiles ni precisos son los abusos que se han introducido en ellas; y el remedio de ello no pende, ciertamente, de satiras é invectivas periodicas. Y sino, digame Vmd. señor sabio universal, estando destinadas las togas, y judicaturas para los que 
profesan la ciencia del derecho (pues no parece regular que se encomiende este cargo á los Chimicos ó á los Comadrones) ¿de qué modo ha de constar que los que aspiren á la judicatura ${ }^{[20]}$ poseen la ciencia suficiente? Vmd. propondrá veinte medios; pero yo estoy pronto á provarle que la carrera de la Universidad es superior á quantas pueda inventar la imaginacion mas fecunda. El que de alli no salga docto en la ciencia que ha de profesar, y exercer, bien puede renunciar á la ciencia, seguro de que por ningun otro medio conseguirá adquirirla. Los grados son la piedra de toque de los adelantamientos; si se dán al baratillo, ese es pan de otra harina; remedielo quien puede, y no confundamos las cosas. Lo mismo digo de la enseñanza de cada ciencia. ¿Es mala? [¿]está corrompida? ahi está la receta de Bacon de Berulamio, que dice, que los Príncipes deben exâminar de quando en quando las escuelas de sus estados, introducir en ellas los progresos cientificos que se hayan hecho; arrancar de ellas abusos, y no dexarlas de la mano; apliquese la receta exactamente, y que me tuesten, si España no es doctisima en menos de 30. años.

Sab[io]. Delirio: bachilleria: esa receta se ha aplicado mucho ha, y no ha surtido efecto.

Es[colar]. Niego esa absoluta. Fuera de que la execucion del remedio se fió á los Doctores viejos de las Universidades, á los que se educaron allá en los tiempos de Gonét, Bartulo, y Riverio. ¿Qué habian de hacer los pobres, si no sabian palabra de lo que se les mandaba enseñar? Consultóseles, y respondieron por lo que sabian: y sobre esto le pudiera yo citar á Vmd. exemplos muy bonitos. El segundo año que fui yo à la Universidad se estableció el estudio de la Filosofia Moral para los Legistas. Parecia regular que el Catedratico fuese un buen jurista, bien instruido en la Filosofia, para que enseñase á sus discipulos la conexion que tiene la Ethica con el Derecho. ¿Mas qué sucedio? La Catedra se dio á un Teologo, y los que estudiabamos entendimos tanto de la utilidad de aquella ciencia para las leyes, como un asno de la armonía de la Lira. Mas con todo ¿cree Vmd. que no se ha adelantado con los golpecitos que se han dado á las escuelas? ¡ojalá hubieran sido un poco mas recios! en fin yo veo que la juventud piensa ya muy distintameme que quando yo concurria á las Aulas.

Sab[io]. Por eso poseemos ya (gracias a Dios) tantos Astronomos, tantos Geometras, tantos Filosofos, tantos:::: 
Es[colar]. Escuse Vmd. el frio catalogo: ¿Quiere Vmd. un Exercito ${ }^{[21]}$ de sabios de esta especie en muy pocos años?

Sab[io]. Vaya un proyecto de Bachiller.

Es[colar]. Pues á fé que es seguro: honra y dinero.

Sab[io]. ¿Todo ha de ser por el dinero?

Es[colar]. Señor mio: ¿por qué se administra justicia en los tribunales? Pues á fé que los que la distribuyen son personas harto graves, y desinteresadas y con todo eso hacen muy bien en tomar las mesadas, y las cruzes quando les condecoran con ellas. Amigo uno ò dos podrán resolverse á seguir las huellas de Cerbantes, conducidos de una fatal inclinacion; pero el comun de los hombres sigue siempre el olor del mando, y las conveniencias. Suponga Vmd. en España quatro Casiris, seis Neutones, ocho Lineos, diez Bufones, doce entre Virgilios, Horacios y Juvenales; y otros tantos entre Libios, Tacitos, y Salustios, que con la mitad nos contentariamos; suponga Vmd. que no tienen mas haberes, ni destino que su habilidad, y que embelesados con sus estudios, ni tienen lugar para pretender, ni aciertan, aunque le tengan. ¿Adónde ha de meter Vmd. esta tropa? Feliz si halla un quartel en que acomodarla. Bien veo que hoy se derraman pensiones sobre esta casta de Profesores, y se ${ }^{5}$ les procura mantener con tal qual decencia; pero, señor mio, los padres que ven el rio de la plata en otras profesiones, las que además conducen á grandes puestos, se guardarán muy bien de inclinar sus hijos á unas ciencias, que por la constitucion actual de las cosas, no condecoran, ni redituan tanto como algunas profesiones, que sin duda son menos utiles. Al contrario los disuaden, y los intimidan con el pronostico de la pobreza que los acompañará infaliblemente. Aquellas ciencias son vagas aun, y fluctuantes: no hay puestos fijos donde se acojan. Y comparado esto con el interes seguro de otras profesiones, ¿qué quiere Vmd. que suceda?

Sab[io]. Con que en fin venimos á parar ¿en qué Vmd. achaca la culpa al Gobierno?

Es[colar]. Distingamos con licencia de Vmd. si habla. Vmd. del Gobierno presente, niego; si de algunos de los pasados, concedo.

\footnotetext{
${ }^{5} \mathrm{En} \mathrm{DiMu}$, 'sè,' por errata.
} 
Sab[io]. A Dios seo Bachiller: no gusto de tratar con aduladores.

Es[colar]. ¿Cómo es eso? juzga Vmd. que está hablando con algun zurzidor de Periodicos?

${ }^{[22]} \mathrm{Sab}[\mathrm{io}]$. ¿A éstos tiene Vmd. por aduladores[?]

Es[colar]. Y mucho: ¿Qué mayor adulacion que quejarse de la ignorancia en las Matematicas, sabiendo que ha muy pocos años que se creia aun en la Astrología, y que no hubo por mucho tiempo en España mas maestro de ellas que Torres? Estos criticos no tiran mas que á las ramas, y á lo que á Dios, y á ventura se les figura allá en su imaginacion que es asunto digno de sus disparos, carocas, y pasmarotas. Mire Vmd. por vida mia que culpa tendrá un rebaño en extraviarse á un matorral donde vé buen pasto ¿si el pastor descuidado le dexa ir?

Sab[io]. Con que....

Es[colar]. Con que lo dicho dicho. En el siglo pasado se fraguó esta fatalidad, que hemos recibido por desgraciada herencia. Los de hoy no tienen la culpa: han aprendido lo que se les enseñaba. Deme Vmd. buen gusto en los maestros publicos; buen orden en los estudios: premios á los que adelanten en las doctrinas verdaderamente utiles, y tratadas como se deben: deme Vmd::: Pero dá la una, tengo que ir á ver á un Ministro para entregarle una esquela de recomendacion. Mañana si Vmd. gusta concluiremos la conversacion á esta hora en este mismo puesto. Agur.

Sab[io]. A Dios seo Bachiller.

\section{${ }^{[27]}$ DIARIO DE LAS MUSAS}

DE 7 DE DICIEMBRE DE 1790.

\section{La Farsa de los Filosofos.}

Jupiter estaba un dia furiosamente enfadado con estos animalejos que se llaman Filosofos, porque no contentos con maldecirse ellos reciprocamente, habian alargado sus habladurías hasta disputarle los efectos de su creacion. ¿Qué desverguenza es esta? (decia á Mercurio vibrando el rayo en ademan de quien obra arrebatadamente) ¿piensan que las obras de un Dios son los tomejos de algun sofista, que han de rebolver sobre ellas, como rebuelven sobre los discursos frios de un academico? Señor (le respondió Mercurio) vos teneis la culpa que 
los habeis hecho hombres, pudiéndolos haber hecho borricos ó avestruces: y por mi la cuenta si ellos os dieran ahora pesadumbre. Vuestra condescendencia ha sido tambien demasiada: vos los habeis dotado de una razon un poco perspicaz, y ellos vanamente ufanos con el don, se os atreven, y os tratan peor que á sus mismos esclavos: os dicen en vuestras barbas, y á rostro firme que los habeis cubierto de miserias; que habeis dado demasiada destemplanza á las estaciones; que la mayor parte del globo la ocupan las aguas, los montes, y los barrancos, que los habeis criado ignorantes, estando en vuestra mano, haberlos criado sapientisimos, y que sé yo quantas otras bachillerías, con que piensan pasar por algo en el espacio de esta inmensidad que los ciñe. Porque habeis de saber, que estos miserables insectillos, si hablan asi de vos, no tanto es por culparos, quanto por hacer creer á los de su especie, que saben mas que el mismo que les dio el ser: tanta es, gracias á vuestro sufrimiento, su vanidad, y majadería.

Jupiter puso malisima cara á este chisme y empezó á pensar seriamente en limpiar la tierra de Sofistas. Estas sabandijas (decia á su hijo) son la langosta de la razon: ¿cómo ha de obrar bien la racionalidad en los demas hombres, si hay sofistas que la corrompan y desvien?

${ }^{[28]}$ Momo (el Zoylo de los inmortales) no pudo al oir esto contenerse en el rincon desde donde habia estado atisvando, y solto una horrenda carcajada. Qué es eso (le preguntó Jupiter). Es (respondió) reirme de vuestra sencillez. ¿Os quejais de que haya sofistas en aquel globillo? [ं]y quién sino vos ha sido la causa de ello? ¿quién os impidió, ó haber negado á los hombres el antojo de curiosear vuestras obras, ó haberles concedido la facultad de comprenderlas, ya que les concedisteis la curiosidad?

Vmd es un pobre hablador forrado en maligno (le dixo Mercurio interrumpiendole) ni Vmd. aqui, ni allá sus Cofrades los sofistas, tienen necesidad de entender los designios de Jove para ser felices en el sitio ò pedazillo de materia que les ha tocado. Si se concedió á los hombres la curiosidad, fué porque su naturaleza la requeria para que viviesen conforme á ella: ¿Qué culpa tiene el Criador, de que ellos abusen de un bien inseparable de su ser? Los que son animales no han nacido para ser Dioses, y ellos por hacerse Dioses se han hecho peores que brutos.

Momo, volvio la espalda sin replicar; pero hallando á la buelta á un Diosecillo su amigo, dicen que le dixo: Mercurio es un fanatico: Se ha empeñado en defender la Providencia de su gran Jove: es menester cubrirle de oprobios, y acallarle á puras bufonadas: El es un Dios de bien; pero adora á Jupiter y no cree en el 
Diccionario de Bayle: En efecto á muy pocos dias se vió el olimpo inundado de epigramas, discursos, pensamientos, ensayos, y otra tal plaga, en que sin entenderse unos á otros los pobres Bachilleres daban sobre Mercurio, y los que con él se habian hecho defensores de la Providencia. El contenido de los librejos era graciosisimo; en unos se afirmaba con gran maestría, que el escremento de las moscas, y de los escarabajos era una parte de la Deidad: en otros, que el degollarse los hombres entre sí, el robarse, calumniarse, y hasta el ahorcarse son cosas que contribuyen grandemente al bien, y perfeccion del mundo: en otros, que los Filosofos, en la esencia, no son mas que unos asnos algo mas perspicaces; en otros, que la felicidad del hombre consiste en que se eche desnudo á pacer cardos en los desiertos. Es increible la fiera turbulencia que levantó la rabia de los criticones de la Divinidad. Jupiter despechado y encolerizado sobre manera, sacudiendo la prepotente cabeza con que hace temblar los exes del Universo, dió una voz espantable, y en ${ }^{[29]} \mathrm{el}$ momento, rasgandose los velos que encubrian la mansion de los Dioses, dexó patente á la vista de estos el granillo de mostaza á que nosotros sus habitadores damos el nombre de globo terrestre y centro del mundo. Ahora vereis (dixo Jupiter á sus ridículos escarnecedores) á que se reduce la sabiduria de estas criaturillas, que habiendolas yo dotado de entendimiento y voluntad para que hiciesen meritorias sus obras, no usan de estas potencias sino para ser ó perversas, ó extravagantes. Fijad la vista en aquella llanura. Fijaronla los Dioses mirones, y vieron un peloton de hombres de diversas condiciones, y cataduras estar deliberando entre sí con mucha seriedad sobre fixar de una vez las leyes de la naturaleza universal, y las de la constitucion humana. Para los Dioses cuya vista se estiende á la vasta capacidad del inmenso espacio poblado de inumerables glovos, era cosa graciosisima ver á unos animalejos que no ven sin anteojos sino lo que tienen á distancia de quarenta ó cincuenta varas, andar muy solicitos y afanados en querer apostarselas en inteligencia al Supremo Hacedor y Moderador de la inmensidad; averiguarle los designios de su Omnipotencia; penetrar los misterios de una Mente infinita, y desentrañar el origen del movimiento y partes de esta maquina indefinida del universo; en la cual es la tierra uno de los anillos mas minimos é imperceptible: hablaban con tal tono los Filosofos, decidian con tanta firmeza, razonaban con tanta satisfaccion de sus bachillerías, que los Dioses se desternillaban de risa á cada instante, viendo la desatinada vanidad de estos pobres hombres, que en vez de seguir los pasos de aquél pedazito de naturaleza que los rodea, y de averiguar sus usos para aprovecharse de sus efectos, se extravian á investigaciones tan 
limitadas tan mezquinas, como la misma capacidad que las cria, y produce. (Se concluirá esta materia en el Núm[ero] 10.).

\section{${ }^{[143}$ DIARIO DE LAS MUSAS}

\section{DE 10. DE DICIEMBRE DE 1790.}

\section{Sigue la Farsa de los Filosofos.}

La escena séria duró un corto espacio entre los graves Filósofos: hicieron quatro cálculos; sacaron á plaza media docena de observaciones, hechas sobre catorce ó quince globos, que del tamaño de unas naranjas brillantes han logrado percivir al cabo de quatro siglos entre la inumerable multitud que puebla el espacio; forjaron ocho combinaciones tan vagas, como la incertidumbre ${ }^{6}$ de sus presupuestos; pusieronse muy ufanos con esta provision de materiales; y, jaquí fue ella! al ponerse á hacer la aplicacion de ellos, fue tal la zalagarda que se levantó entre los criadores de poquito, que enfurecidos y acalorados en la disputa; primero se trataron de ignorantes unos á otros, despues se llamaron bestias, infantes, perjuros, insolentes, sacrílegos, fanáticos, desvergonzados, pillos, y por último apelando de la lengua á las manos y pies, comenzaron á descargarse cachetes, pescozones, cocos y pedradas, con tal furia é impiedad, que compadecido Júpiter al verlos derribados, ensangrentados, cubiertos de polvo y sudor, sacudiendo el rayo, sin dispararle, hizo estallar un espantoso trueno: ¡Santo Dios! ¡quién podrá pintar con dignidad el pavor que se apoderó de los desesperados combatientes! Atolondrados, desatinados sin saber que hacerse, ni donde meterse dieron á huir por la llanura, no del otro modo que en horrida tempestad suelen descarriarse timidas y acobardadas las ovejillas que pacen tranquilas y descuidadas en una pradera: ved (dixo entonces Jove, volviendo la vista con severidad á sus críticos), ved á lo que se reduce la ciencia de los mortales: á costa de desvelos infatigables logran averiguar un cortisimo número de hechos; pero como el conocimiento de las causas está reservado á mí que he creado el universo, y tengo á la vista la inumerable suma de sus partes, colocadas á inmensas distancias en ese inagotable oceano del espacio, del qual no ven los hombres sino ${ }^{[44]}$ una pequeñisima, y casi imperceptible porcion, imposibilitados de comprehender las conexiones; casi infinitas con que están enlazados todos los seres de mi creacion universal, se hechan á adivinar cada uno segun se ajustan los objetos á su limitada mente: Dividense en sectas, propiedad que

\footnotetext{
${ }^{6} \mathrm{En} \mathrm{DiMu}$, 'intercidumbre', por errata.
} 
acompaña siempre á la incertidumbre; el amor propio los instiga á reputar por verdades incontrastables sus opiniones: y al fin, combatiéndose recíprocamente convierten en instrumentos de guerra los medios que debieran servirles para mantener la paz en la tierra. Mercurio vuela y executa mis órdenes. Púsose de punta ácia el glovillo el avechucho de los inmortales, y jugando el caduceo, llegó en un punto al rinconcillo donde se hallaban aun aturdidos los Filósofos. Tomó la figura de un rústico como ocupado en la labor del campo, y recorriendo de uno en uno á todos los Bachilleres, despues de tranquilizados le preguntó separadamente: amigo, vos, que, segun he oido, decis que sabeis mas que yo, y que profesais el oficio de hacer felices á los hombres, decidme por mi vida, ¿soy mas feliz yo, que trabajo para convertir en mi utilidad las producciones de la tierra, viviendo con un grandísimo reposo entre mi familia, ó vos, que embevido ${ }^{7}$ en averiguar las causas de sus frutos, sin saber mejorarlos ni multiplicarlos, vivis en continua discordia con vuestros semejantes? ¿No es bueno que los graves y profundos Filósofos no acertaron á dar una respuesta categórica á esta pregunta? Unos, pronunciaban atraccion, fuerza de inercia, centripeta, centrifuga: otros, torbellinos, materia sutíl: otros[,] monades, armonía: otros, atomos, crepusculos, espectros: hablaban de la paz y de la virtud los que acababan de darse de cachetes: pronunciaban leyes, legislacion, república los que viven entre si en continua guerra, y en un estado de verdadera anarquia. Lo peor fue, que habiendo percibido todos la consulta que á cada uno hacia separadamente el dios disfrazado, volvieron enzarzarse en la disputa, gritando todos a un ${ }^{8}$ tiempo, y hubieran llegado irremediablemente á las manos segunda vez, si desnudándose Mercurio de su disfraz y compareciendo con todo el explendor de su naturaleza no los hubiera contenido con el repentino prodigio. Entonces tomando vuelo y poniéndose sobre sus cabezas, á distancia proporcionada, para que le pudiesen oir, les dixo con tono trágico y amenazador: miserables: qué locura es la vuestra en querer averiguar el poder que tienen las manos del Omnipotente; $[\dot{i}] \mathrm{si}{ }^{[45]}$ entre este poder, y vuestra comprension hay todavia infinitamente mayor distancia que entre el mas mínimo de los atomos y el conjunto entero del universo? ¿Creeis que habeis nacido para saberlo todo porque se os ha dado comprension para saber algo? Júpiter os ha dado las ideas de la verdad para que obreis segun la constitucion que pertenece á vuestra naturaleza: os ha dado la libertad, para que tengais mérito en vuestras obras, y os hagais dignos de una felicidad infinita: os

\footnotetext{
${ }^{7}$ En DiMu, 'embeveoido', por errata.

${ }^{8} \mathrm{En} \mathrm{DiMu}$, 'aun', por errata.
} 
ha dado manos flexibles é ingenio conbinador, para que convirtais en utilidad vuestra los seres de esa habitacion en que os ha puesto mi padre.

La verdadera ciencia, está reducida á estos dos puntos. La virtud, y el trabajo: con observarlos bien, serán felices todos los hombres. El sabio debe emplearse constantemente en promover la virtud, y en investigar los medios de hacer buen uso de los seres terrenos. En pasando de aqui, no son sabios, sino delirantes; no filosofos, sino habladores inutiles, y molestos. Bolved sobre vosotros: comparad vuestra ocupacion ${ }^{9}$ con estos documentos, y resolved qual es el valor de vuestra sabiduria. Si no ${ }^{10}$ lo executais y no os reducis á la verdadera obligacion de sabios, Jupiter está ya cansado de toleraros. Temed sus iras: dixo, y voló rapido á la mansion celeste. Jupiter, cerró entonces su soberano Alcazar. Sus dioses amigos quedaron complacidos con este tapaboca, que dió á sus murmuradores. Estos huyeron á los rincones del olimpo para glosar el caso, con su acostumbrado candor.

\section{${ }^{[145]}$ DIARIO DE LAS MUSAS}

\section{DE 4 DE ENERO DE 1791.}

\section{Diálogo entre el Doctor Ferrando y Mr. Pedant ${ }^{11}$.}

${ }^{[145]} M r$. Es posible que en un siglo tan cultivado como este en que vivimos ¿no querais aun desprenderos de las preocupaciones de los pasados? enagenado con la Biblia, y sus interpretes, vivis en la inteligencia de que en ningun otro libro podreis adquirir las luces que en esos escolásticos; ¡ah! Si tuvierais siquiera una tinturilla de los adelantamientos de nuestro siglo...

Dr. Nunca [he] sido Boticario, Monsieur amigo: Las tinturillas aun en las Boticas son dañosas; ¿qué será en los entendimientos? Entretanto ruegoos que hableis con mas moderacion de unos hombres á quien no habeis conocido jamás, y á quien debeis respetar, y dexadme concluir esta lectura, que requiere alguna mas atencion de la que vos soleis poner en las vuestras.

$M r$ ¡ Bueno por mi vida! y versará tal vez la profunda meditacion sobre utilísimo descubrimiento de alguna nueva forma substancial.

\footnotetext{
${ }^{9} \mathrm{En} \mathrm{DiMu}$, 'ocupucion', por errata.

${ }^{10} \mathrm{En} \mathrm{DiMu}$, 'Sino'.

${ }^{11}$ En el Catálogo de sus obras, antes mencionado, Forner se refiere a este texto como «Diálogo entre un Pretendiente y un Charlatán».
} 
Dr. ¿Y vos me traeis alguna nueva noticia de los habitantes de las estrellas fixas? ¿ó estais meditando algunos comentarios al sapientísimo discurso de aquel vuestro amigo, que ha tenido á bien comunicar á las gentes el util secreto de que los hombres debemos andar como los burros.

Mr. ¿Qué lenguage es ese de doctor Español? La verdad: ¿habeis cometido el sacrilegio de leer á hurtadillas alguno de nuestros libros? Yo sé guardar secreto; no temais: decid...

Dr. [i]Creeis vos que en España se prohibe la lectura de los buenos libros?

Mr. Asi se cree en mi País.

Dr. [i]Excelente prueba! como si no fuera en vuestro País donde se cree que en España sienten las mugeres honestas, que los jóvenes no se atrevan á pedirlas hasta el mayor favor que pueden hacer.

Mr. No lo he experimentado yo asi.

Dr. Y no habrá sido por no pretenderlo; porque vuestra filosofia, creo que no se detiene mucho en estas frioleras.

Mr. Nosotros somos grandes observantes del derecho natural.

Dr. Aun por eso ${ }^{[146]}$ debeis cometer tantos tuertos no naturales: Pero en verdad decidme: ¿Qué fundamento tienen allá vuestros paisanos para creer que en España no se consiente la lectura de los buenos libros?

Mr. La experiencia. Lo primero, allá se cree que la España está sumida en una ignorancia profundísima.

$D r$. Son vuestros paisanos muy benignos para con los extrangeros: proseguid.

$M r$. Esto no puede nacer sino de falta de leer, y esta falta no se puede atribuir á la pereza, ó al poco talento, sino á la escasez de libros. Esta escasez cesaria si pudierais leer $\operatorname{los}^{12}$ nuestros ó los Ingleses.

Dr. ¿Qué libro os parece que es el que tengo en las manos?

Mr. Será sin duda algun Doctor iluminado.

$D r$. Lo fué sin duda, vedle.

$M r$. Las variaciones de Bosuet ya, ya.

${ }^{12}$ En $D i M u$, 'les', por errata. 
Dr. Bosuet, ¿creo que no fue Francés?

Mr. ¿Quién duda de eso?

Dr. ¿Cómo? pues no acabais de decir que en España no se leen Autores Franceses?

Mr. No lo dixe por Bosuet, ni por otros tales como Bosuet.

Dr. Explicaos despacito y entendámonos. ¿Qué libros creen allá que hacen falta á la erudicion de España?

Mr. Dexad que me ria. Creen que hacen falta los Filósofos, los Escritores de buen gusto, los Profesores de bellas letras: que es como decir toda la enciclopedia.

Dr. Enciclopedia me suena á doctrina circular, ó de corrillo: Si es la ciencia de corrillo la que nos falta; amigo, os cedemos de buena gana la gloria de poseerla. No la envidiamos.

$M r$ ¿ ¿Con donayres os venis á un hombre que ha nacido en París?

Dr. Deben de estár vinculados en aquella Ciudad. Hacedme el gusto de registrar aquel estante.

Mr. Aqui veo á Cartesio, Gasendo, Nevvton [sic], Malebranche; Memorias de la Academia de las Ciencias; Muschembrock, Reamur... Esta es la coleccion de Filósofos.

$D r$. Franceses la mayor parte: y coleccion en realidad, porque son escogidos: y creed que todavia todos estos libros no andan impresos en los canceles de los templos.

Mr. Pero andan Lok, Pope, Montesquieu, el autor de Emilio, y otros de esta dignidad.

Dr. Como si dixerais, que ninguna nacion puede ser sábia sin leer esos dignísimos escritores. $[\dot{i}]$ Callais?

$M r$. ¿En que consiste, pues, que en España no se piense y escriba como en otras Regiones?

$D r$. En que en España para escribir piensan mucho, y en otras partes suelen escribir mucho sin pensar.

Mr. Si dixerais que en la falta de libertad de pensar yo os creeria. 
Dr. Poquito á poco que es ese un punto muy deli ${ }^{[147]}$ cado: hacedme el favor de explicarme con claridad y sin rodeo qué entendeis por libertad de pensar.

Mr. Por libertad [de] pensar entiendo que á qualquiera le sea lícito publicar quanto se le ocurriere en materias científicas.

$D r$. Esa mas es libertad de imprimir; pero sea asi en buen hora, y hablemos otras cosas Vos habreis visto ahorcar en la Plaza mayor á varios hombres por salteadores y homicidas: los delitos habrán sido justificados plenamente; pero yo creo que ha sido injusta la sentencia.

Mr. Vos har[i]ais un estupendo depositario del bien comun.

Dr. ¿No os parece? Porque ¿qué razon ha de haber, que por la vagatela de asaltar, y quitar la vida en despoblado á una docena de pasageros, haya de verse un hombre colgado entre dos palos? ¿Y por qué en una nacion culta no se ha de permitir que todo el mundo robe, y mate á su antojo? eso de castigar los hurtos, y homicidios es bueno para los antiguos salvages de Esparta y Lacedemonia, ó para los modernos de la China. ¿Pero en Europa? Digoos, que estamos todavia hundidos hasta el pescuezo en la ignorancia.

Mr. ¡Admirable Legislador! se conoce que teneis una idea clarísima del origen, y bien de las Sociedades.

Dr. Mi imaginacion es poco fecunda: hacedme el gusto de desengañarme si opinais de otro modo. ¿Se podría seguir algun grande inconveniente á una República de que cada individuo pudiese hacer, y obrar á su antojo?

Mr. Ahora me confirmo en que un Teólogo es un animal incapaz de otro fardo que el de su Teología. ¿Vos dudais eso?

$D r$. Qué sé yo que os diga: algunas veces sin estar en mi mano suelo sacár unas conseqüencias malísimas de principios ciertos y recibidos; y si no ved: algunos de vuestros Paysanos, hombres doctos, y graves no hallan inconveniente, en que en una nacion se permita á cada uno la libertad de pensar, esto es, de publicar quanto se le venga á la mollera; y yo no le hallaba, en que á cada uno se le concediese la de hacer quanto se le antojase. ¿Qué os parece?

Mr. Que sois un sofista muy menguádo. Por mi vida; estudiad bien el arte de pensar, y despues disputarémos sobre estos asuntos. 
Dr. Yo no sabia hasta ahora que habia nacido bruto. ¿De qué especie os parece que es aquel animal, que vá arreando á aquel otro animal cargado de coles?

Mr. Quien decís: ¿aquel hortelano[?]

Dr. El mismo.

$M r$. Vos no mereciais ${ }^{[148]}$ ser de su especie quando haceis tal pregunta.

Dr. Sin duda. Pero aquel hortelano no ha estudiado el arte de pensar, y ved aqui otra consequencia de las mias: aquel hombre no pensará no sabiendo el modo.

Mr. ¿Y qué sacais de ahí?

Dr. Que ni aquel hortelano, ni yo pensaremos, puesto que no hemos estudiado el arte. Ahora ved á qué especie de animales pertenecen los que no piensan. ¿Por ventura al Orang-Otang?

$D r$. Vos estais rematado. ¿Es lo mismo, Señor Doctor Español, pensar, que pensar bien?

Dr. ¿Y es lo mismo, Señor Encyclopédico Francés, arte de pensar, que pensar bien? Pues creed, que para pensar aquel hortelano, que la libertad de obrar es dañosa á una República, no necesita del tratado de Puerto Real.

$M r$. ¡Por quánto no habiamos de venir á dar en sutilezas Españolas!

Dr. Nuestras sutilezas son mas sanas, y útiles que vuestros vanos discursos, ridiculamente empeñados en la investigacion de las verdades mas constantes quando se demuestran por sí mismas.

$M r$. Vaya que os veo acalorado, y no quiero proseguir en la materia.

Dr. Pues id con Dios. Mr. amigo, y estudiad mas á fondo las cosas para poder formar el juicio correspondiente de los Españoles. 


\section{BIBLIOGRAFÍA CITADA}

Bolaños Donoso, P. y CAÑas Murillo, J. (2021a): «Juan Pablo Forner en la controversia gaditana de El Filósofo enamorado». Cuadernos de investigación filológica, 49, en prensa.

Bolaños Donoso, P. y CaÑas Murillo, J. (2021b): «Juan Pablo Forner en la controversia madrileña de El Filósofo enamorado». Cuadernos de Estudios del siglo XVIII, 31, en prensa.

CAÑas Murillo, J. (1997): «Una recepción polémica» en su «Introducción». En Forner, J.P.: Oración apologética por la España y su mérito literario. Ed. J. Cañas Murillo. Badajoz: Diputación Provincial (Clásicos Extremeños, 12), 27-29.

JimÉnez Salas, M. (1944): Vida y obras de Juan Pablo Forner y Segarra. Madrid: CSIC (Apéndice 3.․, 589-590).

Piedad Bolaños Donoso
Universidad de Sevilla
piedad@us.es
https://orcid.org/0000-0002-7699-2021
Jesús CAÑAS MURILLO
Universidad de Extremadura
jcanas@unex.es
https://orcid.org/0000-0001-5636-408X

